\title{
Long-term remission of recurren pityriasis versicolor with short-term systemic isotretinoin therapy
}

\begin{abstract}
Although Pityriasis versicolor (PV) well responds to medical therapy, recurrence is a common problem and management of recurrent and chronic PV is a challange. İsotretinoin (13-cis retinoic acid) is a vitamin A derivative, decreases sebaceous gland size and sebum production up to $90 \%$. Although the efficiency of isotretinoin is well known in acne and acne-related disorders, literature regarding its use in PV is scarce. We present here a 33 year-old man succesfully treated and achieved long-term remission with oral isotretinoin therapy who was suffering from diffuse, recurrent PV for nearly 15 years. We believe that low-dose and short-term isotretinoin may be a good therapeutic option for recurrent and chronic PV.
\end{abstract}

Keywords: isotretinoin, long-term remission, pityriasis versicolor, recurrence, therapy
Volume 2 Issue 2 - 2018

\author{
Serkan Yazici, Emel Bulbul Baskan, Hayriye \\ Saricaoglu \\ Department of Dermatology and Venereology, Uludag \\ University School of Medicine, Turkey
}

Correspondence: Serkan Yazici, Specialist, Uludag University school of Medicine, Department of Dermatology and Venereology, 16059, Bursa/Turkey, Tel +9022 4429 50721, Fax +9022 4442 9229, Email serkanyazici@uludag.edu.tr

Received: September 28, 2017 | Published: March 14, 2018

\section{Introduction}

Pityriasis Versicolor (PV) is a common chronic benign superficial fungal infection, characterized with scaly hypo/hyperpigmented macules. The causative agents are saprophytic, lipid-dependent yeast of Malassezia Genus. Colonization by these species is mainly localized to the scalp, upper trunk and proximal extremities, body areas rich in sebum. ${ }^{1}$ PV usually responds well to medical therapy and many traditional treatment options are available. Although spontaneous remission has been reported, recurrence is a common problem and management of recurrent and chronic cases is a therapeutic challenge. ${ }^{2}$ We present here a 33 year-old man succesfully treated, and achieved long-term remission with oral isotretinoin therapy who was suffering from diffuse, recurrent PV for nearly 15 years.

\section{Case report}

A 33 year-old male was admitted to our outpatient clinic with complaints of diffuse scaly mild pruritic macules, coalescing on upper trunk and spreading to neck. His lesions were recurring for 15 years. Medical history revealed the use of many topical and systemic antifungal agents as well as topical retinoic acids for treatment with partial benefit. Recurrence of the lesions were common after withdrawal of therapy. Microscopically short, thick fungal hyphae and variable sized spores were observed. The patient was hospitalized for recurrent PV and laboratory investigations were performed. Any underlying disease and immunodeficiency was not found. Oral isotretinoin therapy at a dose of $20 \mathrm{mg} /$ day $(0,4 \mathrm{mg} / \mathrm{kg} /$ day $)$ was initiated. His lesions completely disappeared within 6 weeks. After two months of therapy, he stopped the drug. He is still lesion free in the one-year follow up period without any drug use.

\section{Discussion}

Isotretinoin (13-cis retinoic acid) is a vitamin A derivative, which has been successfully used in severe, recalcitrant nodulocystic acne since 1971. ${ }^{3}$ The drug decreases sebaceous gland size (atrophy) and sebum production up to $90 \%$. Within 1 month after cessation of therapy, sebum production returns to about $40 \%$ below baseline levels, and never reaches the initial levels again. ${ }^{4}$ Long term remission maintained with isotretinoin therapy may be explained by this hypothesis. Isotretinoin has been effectively used for the management of seborrheic dermatitis, pitrosporium folliculitis, recalcitrant acne and hidradenitis suppurativa by the same mechanism in the literature. ${ }^{5,6}$ Bartell et al. ${ }^{7}$ were the first to report an incidental clearance and remission for 9 months of pre-existing PV during the treatment of acne vulgaris with oral isotretinoin $40 \mathrm{mg}$ bid. Our case was succesfully treated with oral isotretinoin therapy at a dosage of $20 \mathrm{mg} /$ day $(0,4 \mathrm{mg} / \mathrm{kg} /$ day $)$ for $2 \mathrm{months}$ and long-term remission was achieved for one year. Besides the well-known efficacy of isotretinoin at doses of 0.5 to $1.0 \mathrm{mg} / \mathrm{kg} /$ day in the treatment of acne, MandekouLefaki et al. ${ }^{8}$ reported that lower doses may also be effective with a dosage of 0.15 to $0.4 \mathrm{mg} / \mathrm{kg} /$ day. Geissler et al. ${ }^{9}$ reported that very low dose of isotretinoin at a dosage of $2.5 \mathrm{mg} / 3 \mathrm{x}$ weekly is effective in controlling seborrhea. Layton et al. ${ }^{10}$ reported that majority of the patients experienced long-term improvement in acne severity after low dose isotretinoin therapy. Although the efficiency of isotretinoin is well known in acne and acne-related disorders, literature regarding its use in PV is scarce. Probable mechanism underlying the effectivity and long-term remission of isotretinoin in PV is seems to be related with the decreases in sebum production and sebaceous gland atrophy further studies are needed for the establish the optimal dosing and duration of therapy. We thought that low dose and short term isotretinoin may be a good therapeutic option for recurrent and chronic PV.

\section{Acknowledgements}

None.

\section{Conflict of interest}

The authors declared that there are no conflicts of interset. 


\section{References}

1. Gupta AK, Batra R, Bluhm R, et al. Pityriasis versicolor. Dermatol Clin 2003;21(3):413-429.

2. Robertson LI. Itraconazole in the treatment of widespread tinea versicolor. Clin Exp Dermatol. 1987;12(3):178-180.

3. Pochi PE, Shalita AR, Strauss JS, et al. Report of the Consensus Conference on Acne Classification. Washington, D.C., March 24 and 25, 1990. J Am Acad Dermatol. 1991;24(3):495-500.

4. Kraus SJ. Stress, acne and skin surface free fatty acids. Psychosom Med. 1970;32(5):503-508.

5. Friedman SJ. Pityrosporum folliculitis: treatment with isotretinoin. $J$ Amer Acad Dermatol. 16(3 Pt1):632-633.
6. Cowley NC, Farr PM, Shuster S. The permessive effect of sebum in seborrheic dermatitis: an explanation of the rash in neurological disorders. Br J Dermatol. 1990;122(1):71-76.

7. Bartell H, Ransdell BL, Ali A. Tinea versicolor clearance with oral isotretinoin therapy. J Drugs Dermatol. 2006;5(1):74-75.

8. Mandekou-Lefaki I, Delli F, Teknetzis A, et al. Low-dose schema of isotretinoin in acne vulgaris. Int J Clin Pharm Res. 2003;23(2-3):41-46.

9. Geissler SE, Michelsen S, Plewig G. Very low dose isotretinoin is effective in controlling seborrhea. J Dtsch Dermatol Ges. 2003;1(12):952-958.

10. Layton AM, Knaggs $\mathrm{H}$, Taylor $\mathrm{J}$, et al. Isotretinoin for acne vulgaris-10 years later: a safe and successful treatment. Br J Dermatol. 1993;1290(3):292-296. 